\title{
Appropriate emotions and the metaphysics of time
}

\author{
Olley Pearson ${ }^{1}$
}

Published online: 24 June 2017

(C) The Author(s) 2017. This article is an open access publication

\begin{abstract}
Prior used our emotions to argue that tensed language cannot be translated by tenseless language. However, it is widely accepted that Mellor and MacBeath have shown that our emotions do not imply the existence of tensed facts. I criticise this orthodoxy. There is a natural and plausible view of the appropriateness of emotions which in combination with Prior's argument implies the existence of tensed facts. The Mellor/MacBeath position does nothing to upset this natural view and therefore is not sufficient to block one drawing conclusions for the metaphysics of time from the nature of our emotions.
\end{abstract}

Keywords Time $\cdot$ Tense $\cdot$ Emotions $\cdot$ Prior $\cdot$ Mellor $\cdot$ MacBeath

\section{Introduction}

Our emotions ground a proof that tensed language cannot be reduced to or translated by tenseless language, as has been shown by Prior. However, it is widely accepted that Mellor and MacBeath have shown that our emotions do not imply the existence of tensed facts. In this paper I will show that they are mistaken. There is a natural and plausible view of the appropriateness of emotions which in combination with Prior's argument implies the existence of tensed facts. The Mellor/MacBeath position does nothing to upset this natural view and offers nothing of equal explanatory force therefore it does not undermine the implication that tensed facts exist.

The content of this paper is as follows. Section 1 outlines Prior's argument for the impossibility of translation and potential implications for the metaphysics of

Olley Pearson

f.o.c.pearson@durham.ac.uk

1 Department of Philosophy, Durham University, 50 Old Elvet, Durham DH1 3HN, UK 
time. Section 2 gives Mellor's initial response and the improved Mellor/MacBeath response. Section 3 argues that our everyday behaviour implies a view of emotions according to which our emotions are justified by the facts that they are responsive to. Sections 4.1 and 4.2 argue tensed emotions have different patterns of justification from tenseless ones. If the view of emotions outlined in Sect. 3 is adopted, it hence follows that tensed emotions must be responses to different facts from tenseless emotions, moreover, these tensed facts must obtain given many tensed emotions are appropriate. Section 5 highlights some other inadequacies of the Mellor/MacBeath account. The conclusions of the paper are that our everyday treatment of emotions can ground an argument for tensed facts and that the Mellor/ MacBeath response to Prior is inadequate. For want of space this paper doesn't settle every detail of this view of emotions or hence conclusively establish the existence of tensed facts but it makes a valuable first step by showing how such a view of emotions fits our everyday practices and establishing that the issues raised by Prior's paper have not yet been settled.

\section{Expressing emotions, translation, and tense}

According to the tensed view of time, tensed language captures facts that tenseless language cannot. Linguistic tense maps onto something in the nature of time itself capturing a metaphysical tense. This is denied by the tenseless theory of time that takes tensed and tenseless language to capture the same tenseless facts.

The tenseless theory would be proven if all tensed language could be translated by tenseless language. The view that such translation is possible-the old-tenseless theory-was common in the first part of the last century. It was suggested that a translation of a tensed utterance could be provided by a tenseless utterance that included the date of the utterance or an explicit reference to the utterance (Cf. Russell 1906; Goodman 1951; Reichenbach 1948). Prior disagreed and on the basis of our expression of our emotions argued that tensed language can be used on occasions when tenseless language cannot and hence that they must mean different things.

Prior considers a case in which he says "Thank goodness that's over". ${ }^{1}$ Not knowing the date, Prior would not say "Thank goodness the date of the conclusion of that thing is the 15th of June, 1954" even though that was when he was speaking. Nor is Prior particularly concerned that he makes that utterance [or has that relief/belief] then and he would not say something like "Thank goodness the conclusion of that thing is before this utterance [belief/relief]". In short, the emotion expressed by Prior's tensed utterance is not equally expressed by any tenseless alternative (Cf. Prior 1959, 1962).

This entails that the old-tenseless theory is wrong and that we do not have a quick proof that there are no tensed facts. However, given that Prior's expression was true

\footnotetext{
1 Prior was not the first to make use of such a comment in the context of debates about time. Broad (1938: 267) uses a similar example. (I am grateful to an anonymous referee for pointing this out).
} 
and was appropriate a further issue is raised for the tenseless theory: how could Prior's emotion be appropriate and its expression true when there are no tensed facts? This issue needn't arise for the tensed view which is hence put at an apparent advantage.

\section{Mellor's initial response and the improved Mellor/MacBeath response}

Mellor's initial response to Prior's case was to distinguish the tensed utterance "that's over" from the utterance of "thank goodness" which expresses relief (Mellor 1981a, b ch. 3). Mellor said that the tensed utterance could be true even if there are no tensed facts because we can provide tenseless truth-conditions for tensed utterances. For example, an utterance, $u$, of ' $e$ is over' will be true if and only if $u$ is after $e$. So Prior's utterance will be true because it is after the end of the exams which are its subject. (From here on I will refer explicitly to the exams for clarity and to avoid adding unnecessary complexities brought in by the use of the demonstrative). Being after the exams is a tenseless fact and so we do not need tensed facts to make the utterance true. Mellor says that relief is appropriate after a painful experience and therefore the relief Prior expresses is appropriate as it is after the exams. Again, the fact that the relief is after the exams is a tenseless fact and so we do not need tensed facts to account for the appropriateness of Prior's relief.

The strength of Mellor's response lies in his recognition that two expressions might mean different things but be made true by the same facts. In making this move Mellor is taking us away from the old-tenseless theory toward the newtenseless theory. The new-tenseless theory accepts that tensed language cannot be translated by tenseless language but denies that a difference in meaning need entail a difference in truth-maker (rather, asserting that the truth-makers for all language are tenseless facts). ${ }^{2}$ Coinciding with this separation of meaning and truth-makers the new-tenseless theory recognizes the non-extentionality of propositional attitudes. Two propositional attitudes might concern the same facts without the subject of those attitudes being aware of this (for example, even though Carroll is Dodgson, Tim might believe that Carroll wrote fiction but not that Dodgson did). (From here on, when speaking of the tenseless theory I mean the new-tenseless theory). ${ }^{3}$

MacBeath, however, argued that Mellor's initial response is inadequate because it is false to think that the relief has no content. Prior is clearly relieved about something (MacBeath 1983). Moreover, if we accept that the relief has a content it is clearly a tensed one as Prior is relieved that the exams are over and he is not

\footnotetext{
2 Although Mellor gives his initial response using the notion of truth-conditions, he later switches to speaking of truth-makers because he finds the latter terminology more explicit (cf. 1998: xi). I am sympathetic to this idea and so adopt the truth-maker terminology to increase clarity without changing the substance of the argument.

3 The refutation of the old-tenseless theory is generally accepted (cf. Oaklander and Smith 1994).
} 
relieved that they finish before a certain date or before a specific utterance (or any other entity).

MacBeath offered a different tenseless solution. He pointed out that belief is an essential intermediary between the facts one is relieved about and the relief one has as a result. If Prior did not believe the exams were over, he would not be relieved that they were. Moreover, the relief is responsive to the belief not the fact believed because one could falsely believe the exams to be over and resultantly be relieved. The tenseless theorist can thus say that Prior's relief has a content, namely that the exams are past, and this is a tensed content. However, in order for Prior to be so relieved it is not necessary for a tensed fact to obtain. It is sufficient that he has a belief with a tensed content. Moreover, this belief can be true and made true by tenseless facts as outlined by Mellor. Prior's relief that the exams are over is also appropriate because relief that the exams are over is appropriate after the exams, which is a tenseless fact. This solution has been adopted quite generally by tenseless theorists including Mellor (cf. Maclaurin and Dyke 2002; Mellor 1983 respectively).

\section{Clarification of Mellor/MacBeath and an everyday view of emotions}

MacBeath has rightly argued that Prior is relieved about or for something, namely the fact that the exams are over. I will refer to this as the object of his relief or belief. It is that aspect of the world-fact-that he is responding to. This notion of object should be distinguished from the notion of content. ${ }^{4}$ By the content of a belief I mean its intentional aspect or meaning, or its propositional content on some understandings of that notion. This notion of content is important when considering the new-tenseless theory as it allows one to say that two expressions or propositional attitudes can have different contents but the same object. The Mellor/MacBeath position as I understand it is that Prior's relief has a tensed content but a tenseless object.

MacBeath actually allowed for two alternatives: either for tensed and tenseless beliefs to differ in content but coincide in object; or for them to differ in content and object, but for the object of a tensed belief not to exist as tenseless facts can make tensed beliefs true. MacBeath's openness on this is reflected in his discussion of the notion of fact where he offered two alternatives: tensed facts can be understood to be merely intentional (thus rendering tense an aspect of the content), or they can be understood to be such that they are not intentional but such that they are merely supposed facts (thus rendering tense an aspect of the object, but an object that does not obtain) (MacBeath 1983). (I will reserve the term 'fact' for such states of the

\footnotetext{
${ }^{4}$ I intend this notion of content to be broad and hence it may not coincide with other uses of the term in the literature. For example, when Kaplan (1989) speaks of content he means propositional content allowing tensed and tenseless expressions to differ in character but not content. However, for Mellor (1998) tensed and tenseless expressions will differ in the propositions they express. Content, as I understand it, is such that both Kaplan and Mellor take tensed and tenseless expressions to differ in content.
} 
world as occur in MacBeath's latter use. By 'fact' I mean something objective and metaphysically real). ${ }^{5}$ The position I refer to as the Mellor/MacBeath position is the one of these alternatives that I take Mellor and many others in the literature to adopt. However, the fact that MacBeath offered two distinct tenseless answers does not appear to be recognized in the literature. As will become clear, the arguments I give below show both alternatives to be inadequate.

The object of Prior's relief plays an important role in the justifying of his emotion. It is a role not played by the content of his emotion. (This is what enables me to argue below that the Mellor/MacBeath position is ultimately inadequate because it focuses on content.) The object of Prior's relief is the reason for Prior's relief. It is that for which he feels relief and it is that to which he will refer if someone asks him why he is relieved. It is the motivational reason for Prior's emotion. On this occasion the fact which is the object of his emotion is also that which justifies Prior's relief. If Prior is relieved the exams are over and they are over, then his relief is justified.

On this occasion the fact that the exams are over plays three roles: it explains why Prior is relieved, it motivates his being relieved [is the motivational reason or object], and it justifies his being relieved [is the justificatory reason]. ${ }^{6}$ It should not be a surprise that these three roles are played by the same thing on this occasion. Prior's being motivated by this fact is no doubt linked to this fact's justifying such relief. Prior knows that exams being over justifies relief and this knowledge is reflected in his being relieved that the exams are over (in his relief having that fact as object). Further, it is because the fact motivates Prior's relief that the fact can explain his relief. This is not to say that these three roles will always be played by the same thing. Someone might be motivated by something which does not justify them, justified by something that does not motivate them, or we might explain someone's movements without any mention of what motivates them (for example, with a purely physiological explanation in terms of muscle contractions and neuron firings). ${ }^{7}$

MacBeath at times spoke of the object of Prior's relief as being a merely intentional entity such that the intentional entity that the exams are over can exist even though the exams are not over (MacBeath 1983: 86). ${ }^{8}$ But, the object of Prior's relief is clearly not an intentional entity. If we told Prior that the exams were not over he would not see there to be any reason for his relief and his relief would disappear even if we told him that the intentional entity that the exams are over still exists. (That the intentional entity would continue to exist is even quite plausible if

\footnotetext{
5 Cf. Mellor's strong, truth-maker notion of fact (1998: 25).

6 This talk of having an emotion for a reason is not undermined by data that emotions begin before a cognitive element kicks in (cf. Damasio 2000), rather, it is plausible that by emotion we mean something more than this initial physiological change (it is insofar as they are cognitive and protracted that they are the focus of normative evaluations) (cf. Solomon 2004).

7 Cf. Alvarez (2009).

${ }^{8}$ Cf. Solomon (1993), especially chapter 5, who takes the object of an emotion to be something subjective and who I believe is shown to be mistaken in just the same way as MacBeath.
} 
intentional entities are abstract entities, as they appear to be.) Prior's relief is responsive to the facts not to a merely intentional entity.

Similarly, Prior should not be relieved that the exams are over if they are not over whether or not an intentional entity exists. So it is clear that the justificatory reason for his emotion is also a fact. That the object of Prior's emotion (i.e. his motivational reason) and his justificatory reason are both facts is of little surprise. If motivational and justificatory reasons were thought to belong to two distinct categories of entity, then no one would ever be motivated by something that justified them. ${ }^{9}$

The object of Prior's relief is thus clearly not an intentional entity. It is a state of the world or fact. This is clear for two reasons. First, Prior's relief tracks the facts. This tracking is mediated by belief, however, so can be unsuccessful when the relevant belief is false. Second, justificatory reasons for emotions are facts and it must be the case that Prior is motivated by the kind of thing that justifies him if his relief is appropriate.

This is to adopt a form of externalism ${ }^{10}$ about what motivates and justifies emotions. ${ }^{11}$ Emotions are motivated and justified by facts. Emotions are responsive to the world and it is in this responsiveness that their justification lies. This externalism is apparent in our everyday talk and interactions quite generally. It is central to our practices of explaining and justifying emotions. The fact that my grandmother has died justifies and motivates my grief. It leads me to cry and others to take that crying to be appropriate and to comfort me. Furthermore, if she had not died, I shouldn't have been grieving her. The fact that my neighbour has chopped down my tree justifies and motivates my anger, and so on. This externalism is closely related to externalism about the motivational and justificatory reasons for actions. The fact that a car is speeding towards me both motivates and justifies my action of jumping out of the road. ${ }^{12}$

As with reasons for action, the strongest criticism of an externalism about motivational and justificatory reasons for emotions concerns error cases. For example, suppose that Prior believes the exams are over and as a result is relieved but the belief is mistaken and the exams are still in progress. It appears that the fact that the exams are over could not be what motivates Prior because this fact does not obtain. One might therefore conclude that it must be something else that motivates him and the obvious candidates are his belief or relief that the exams are over, or its

\footnotetext{
9 Cf. Dancy (2000: ch. 5).

${ }^{10}$ The externalism at issue is specifically a form of non-psychologism about reasons. Reasons are facts, as opposed to mental states, such as complexes of beliefs and desires [for a similar take on externalism one might look to Dancy (2000); the opposing view that reasons are mental states is classically given by Davidson (2001a)]. This use of the term 'externalism' differs from some others in the literature, such as Williams's which is in part bound with other issues to do with the nature of motivation (cf. Williams 1979).

11 This externalism at least characterizes an important class of common emotions (for example, grief, relief, anger, jealousy, envy, gratitude, fear, anticipation, and so on), though I do not mean to assert that it will fit every state that might be thought of as an emotion (perhaps, for example, depression is an exception).

12 Cf. Dancy (2000) and Alvarez (2010).
} 
content the intentional entity that the exams are over, contra externalism. (MacBeath separated the relief and the belief. On certain cognitive views of emotion there is no need to make this separation, rather emotions can have a content as beliefs can. I will not take sides on this issue ${ }^{13}$ and so will speak of emotions and beliefs, but my argument works on either view). ${ }^{14}$

The correct thing to say in an error case is, however, not that Prior is motivated by his relief/belief or an intentional entity, but that his relief has no object. The relief is not motivated by anything because the belief involved is mistaken. What Prior cites as his motivating reason does not exist and we should take this at face value. Being motivated by is a case of taking an attitude towards and it is quite possible to take an attitude towards a non-existent. ${ }^{15}$ This might require an intentional entity to exist but this does not require that the intentional entity is what the attitude is about. In other words, this might require content but it does not require that the content is the object. Further, the relief is not justified by anything either because it is not justified at all because the exams are not over.

There is perhaps a sense in which the relief is excusable if the false belief is held but this excusableness is a separate matter and furthermore arguably derives from the fact that were the belief true the relief would be justified. (This last comment highlights that externalism isn't committed to the implausible idea that so long as an emotion is motivated by a fact it is appropriate. Rather, an emotion will be appropriate when it is motivated by a fact which justifies emotions of that sort or, putting the point differently, when the object is a justifying reason). ${ }^{16}$

Nevertheless, MacBeath was right that Prior might mistakenly believe the exams to be over when they are not over and as a result he might become relieved. The belief that they are over or its content thus appears to play a role in the origin of Prior's relief. However, we have seen that neither the belief nor its content is the object of Prior's relief. It is not the reason for which he is relieved. Nor is the belief or its content what justifies Prior's relief either in the error case or the one actually at hand.

In summary, MacBeath was right to bring Mellor around to the idea that Prior's relief has an object. However, our everyday practices give this object a role that the Mellor/MacBeath position makes little recognition of. In particular, the object of an emotion is what motivates it and therefore it is also what justifies the emotion if that emotion is appropriate. Further, the entities that play the role of objects are facts and

\footnotetext{
13 My argument does show that the appropriateness of an emotion cannot simply be identified with the appropriateness of the belief it involves; it might be appropriate to believe my grandmother will die, but not to grieve that she will [this perhaps stands against ideas found in, for example, Greenspan (2004)].

14 The belief is distinct from the fact that the belief is had (just as my car is distinct from the fact that I own it). Externalism could allow that the fact that Prior believes the exams are over is a motivating and justifying reason for an emotion, for example, if Prior's belief is mistaken, the fact that he has it is a reason for me to worry that I am going to have to correct him.

15 Cf. Alvarez (2008). It is wrong to think that the object of motivation must exist in order to cause the motivation, as is made clear by the fact that one can be motivated by future events.

${ }^{16}$ For example, endings of discomforts of ours are reasons for us to be relieved (cf. MacBeath 1983), loses of ones we love are reasons for us to grieve, and so on.
} 
hence clearly not the contents of emotions so long as contents are merely intentional entities.

\subsection{Appropriate tensed emotions concern tensed facts: inadequacy of denying the object exists}

As outlined above, the second of MacBeath's tenseless responses to Prior's case involved taking the object of Prior's relief to be a tensed fact but denying that that fact obtained (or, more accurately, denying the relief had an object but accepting that if it did it would have been a tensed fact). ${ }^{17}$ However, in this section I will argue that this response to Prior is problematic. In particular, denying that any tensed emotions have existent objects entails that one cannot refer to the object of a tensed emotion to account for its justification or appropriateness, contra the account of emotions outlined in Sect. 3. (Where, specifically, a tensed emotion of relief is one that can only be accurately expressed or captured with tensed language as Prior's is and a tenseless one is one that can only be accurately expressed or captured by tenseless language).

According to the everyday account of emotions outlined just above an emotion is appropriate if it is motivated by a fact that justifies an emotion of that sort: that is, if the object of the emotion is a justificatory reason for that emotion. It follows that an emotion that lacked an object [or whose object was a non-obtaining fact] would not be an appropriate emotion. A tenseless response to Prior's case that took the line that no tensed emotions had objects would hence entail that no tensed emotions were appropriate. However, there clearly are cases of appropriate tensed emotions because Prior's relief is an example. Therefore, this tenseless response is no good. Denying that Prior's relief has an existent object implies that Prior can be relieved because of something and that thing not obtain and his relief nevertheless be appropriate. But this is false. If the exams are not over, then Prior oughtn't to be relieved that they are.

One might think that my last sentence is mistaken because coherence between beliefs and emotions is important and so there is a sense in which it ought to be the case that if Prior believes the exams to be over then he is relieved (whether or not the exams really are over). I am not sure such a conditional is correct but even if one did accept it it needn't negate my point because it is not clear one can detach the 'ought' and apply it just to the consequent of the conditional. ${ }^{18}$ That is, it might be true that it ought to be the case that if Prior believes the exams to be over then he is relieved; that Prior does believe the exams to be over; and that it is not the case that Prior ought to be relieved. This is because the 'ought' applies to the conditional as a whole and cannot be detached and applied just to the consequent of the conditional. More specifically, it ought to be the case the conditional is satisfied but it could be satisfied by Prior not having the belief and, as it happens, this is the better way to

\footnotetext{
17 As noted above, I do not take this to be a response that is widely adopted in the literature, nevertheless, it is a tenseless response as it denies that there are any tensed facts and it is a response that was given by MacBeath so it is worth discussing.

18 Cf. Dancy (2000: chs. 2 and 3), and, Broome (2001).
} 
satisfy it on this occasion. ${ }^{19}$ If we came across Prior in such a situation we would assume that he oughtn't to be relieved and that he oughtn't to have the belief. Our reaction would be to correct his mistake in both respects.

Furthermore, if the [would be] object of Prior's relief that the exams are over is a tensed fact, this entails that Prior's belief that the exams are over serves to pick out that tensed fact. The tenseless theorist's insistence that Prior's tensed belief can be true thus absurdly implies that the belief can be true despite the fact which is its object failing to obtain. But this is clearly wrong. If the tensed fact which is the object of Prior's tensed belief does not obtain then the belief is false. The object here is not merely pragmatically implied by the belief, as if it arises as a side effect of the belief or emotion. Rather, it is what the belief or emotion is concerned with.

The point of the last paragraph might be put this way: even if we can state tenselessly conditions which must be fulfilled for a tensed belief to be true, as Mellor argues we can, there still remains the question of whether the satisfying of these conditions is what makes the belief true in the sense of actually grounding the truth. It is clear that it might be that a state necessarily obtains if and only if a belief would be true without it being the case that that state is the truth-maker of such beliefs. For example, it is arguably necessary that the fact that one plus one is equal to two obtains if and only if a belief that three plus three is equal to six would be true, but that latter fact would not make such a belief true. Alternatively, the fact that an electron has spin obtains if and only if a belief that that electron has charge would be true, but it is not the case that the fact that an electron has spin is the truthmaker of beliefs that that electron has charge. The point is simply that various facts can be necessarily coincident with other facts and therefore with the truth of certain beliefs without being the truth-makers of those beliefs. ${ }^{20}$ Once a tensed fact is recognized as the object of the tensed belief the tensed fact appears to ground the truth of the tensed belief whilst the tenseless truth-conditions merely appear to be such that they necessarily obtain if the belief is true.

If we recognize a tensed fact to be the [would be] object of Prior's tensed belief and we say that that tensed fact does not obtain, then we must say that Prior's belief is false. If Prior's tensed belief is false, then arguably so too are most other tensed beliefs because we can rerun Prior's argument for different events. But this is unacceptable because all of our perceptual beliefs are tensed and so we would be thrown into a thorough scepticism.

Thus, there are two reasons why the tenseless theorist cannot account for Prior's argument by referring to a tensed fact as the object of his relief and denying that fact

\footnotetext{
19 This might make it sound as if the conditional has normative, justificatory import in this case, contra to my suggestion that it is the object of, or reason for, the emotion which has justificatory import. However, this is incorrect. Rather, I believe conditionals such as the one discussed in this paragraph can be shown to have no normative import of their own, instead they merely reflect the import of reasons. If one has conclusive reason to believe the exams are over, one will also have reason to be relieved that they are over, and if one does not have reason to be relieved that they are over, then one will not have conclusive reason to believe that they are over. It is this nature of reasons that lies behind the conditional that one ought to be relieved if one believes the exams to be over, and which gives rise to any normative force the conditional might be thought to have (Cf. Kolodny 2005, 2008).

${ }^{20}$ Cf. Lowe (2009).
} 
obtains. First, this would entail that no tensed emotions were ever appropriate which is contra to fact as Prior's appropriate relief makes clear. Second, this would imply that all tensed beliefs were false which is contra to fact as Prior's true belief that the exams are over makes clear.

\subsection{Appropriate tensed emotions concern tensed facts: inadequacy of tenseless objects}

According to the first of MacBeath's tenseless responses to Prior's case, the Mellor/ MacBeath response, a tensed emotion has a tensed content but a tenseless object. In this section I will argue that this response to Prior fails. My argument will have the following form: according to the everyday view of emotions emotions are made appropriate by their objects; no tenseless emotions of relief are appropriate; therefore, no tenseless emotions of relief are made appropriate by their objects; therefore, the objects of tenseless emotions of relief are not justificatory reasons for relief; according to the Mellor/MacBeath tenseless theory tensed and tenseless emotions of relief share [tenseless] objects; therefore, no tensed emotion of relief has a justificatory reason for relief as an object; therefore, no tensed emotion of relief is appropriate; however, there are appropriate tensed emotions of relief; therefore, the tensed and tenseless emotions of relief must have different objects and the Mellor/MacBeath tenseless theory is mistaken.

If we take the object of Prior's relief to be a tenseless fact we will be unable to appeal to this object to account for the justification of Prior's relief or to provide the reason for which he formed that relief. Before the exams are over Prior may well know, and I shall suppose that he does know, that they finish before the date he feels relief (perhaps he knows from past experience that he will feel relieved when they are over). Despite this knowledge, Prior does not feel relieved until the exams are over and nor is Prior justified in feeling relieved that they are over until they are. The problems here stem from the fact that many emotions have a temporal orientation. Relief is orientated towards the past. One is justified in feeling relief when something bad has ended but not before it has. ${ }^{21}$

Prior not only denies that he has an emotion of relief that can be captured with tenseless language, he actually questions why anyone would have such an emotion. $^{22}$ I take this to raise the issue not only that these tenseless emotions of relief would be odd, but further that they would be inappropriate. It is appropriate to be relieved that a discomfort has ended but it is inappropriate to be relieved that a discomfort will end. ${ }^{23}$ In a connected manner, it is inappropriate to have a tenseless

\footnotetext{
${ }^{21}$ Mellor takes his masochists to be a counter example to this, I, as was MacBeath, am less convinced. Rather, perhaps the better thing to say is that the masochist is relieved that the negative state of lacking pleasure in having pain has ended. At any rate, the argument works just as well with the case of grief, as it does with relief, and here there is no such exception.

22 Cf. Prior (1959: 17).

23 Even if it is appropriate to be relieved to have learnt that a discomfort will end, for example, be relieved when one's discomfort at the prospect of endless discomfort ends. Hoerl (2013) in fact distinguishes two forms of relief, temporal and counterfactual. If this distinction were accepted my
} 
emotion of relief because in such tenseless relief one will not know whether or not the discomfort has ended. Just as Prior's relief is inappropriate if the exams are not over, it is also inappropriate if he does not know whether they are.

One could have tenseless beliefs that a discomfort ends at a certain time or simultaneously with a certain feeling of relief or belief, and also not know whether that discomfort has ended. In support of this, suppose that mental states are brain states $^{24}$ which can be seen in brain scans. One might then point to a screen and refer to and have a belief/emotion about a pictured brain state without knowing it was one's own and if one did not know whether the broadcast was live, without knowing if the state was present. In this way emotions can be responsive to tenseless facts and ignorant of tensed ones. Tenseless relief thus lacks a sensitivity to whether a discomfort has ended yet it is precisely a sensitivity to this that makes a relief appropriate. (It is important to note that all parties must agree that it is true to say some things are past and others are not, and therefore these comments do not presuppose a tensed theory of time.)

Relief is only appropriate when orientated towards the past. Many other emotions are also temporally orientated. Some are orientated towards the past and others towards the future or present. Fear is only appropriate when one is or will be in danger. ${ }^{25}$ This temporal orientation is embodied in the fact that one must be sensitive to time in having these emotions if one is going to be appropriate. One is only so sensitive if the emotions are tensed because tenseless emotions, precisely in being tenseless, are not so sensitive. (Because of this, one could construct an argument analogous to the one I have here concerning Prior's relief using a number of different cases: my grief that my gran has died, my anticipation of Mellor's response, and so on.)

One might be put in mind of Perry's cases of the essential indexical (Perry 1979). Perry argued that we cannot explain a professor leaving his office for a $12 \mathrm{pm}$ meeting by referring to his tenseless beliefs, such as that 'meeting $\mathrm{N}$ starts[tenseless] at $12 \mathrm{pm} 7 / 7 / 17$ ' or 'to attend meeting $\mathrm{N}$ an individual must leave[tenseless] their office at $12 \mathrm{pm} 7 / 7 / 17,{ }^{26}$ The reason for this is that the professor might well have these tenseless beliefs and not be at all motivated to leave his office despite wanting to attend the meeting. This is because one can have these beliefs at any time as being tenseless their truth and appropriateness is not time sensitive. In fact, we can suppose the professor has these tenseless beliefs all morning before the meeting. To make sense of the change in behaviour of the professor, of his standing to leave his office, we must suppose that he forms a relevant tensed belief such as that

Footnote 23 continued

argument might only apply to the former sort but this is the sort had by Prior and therefore it is the sort that is the subject matter of this paper.

24 My argument does not rest on this assumption, just the idea that mental states can be known thirdpersonally as well as first-personally.

25 Cf. Cockburn (1998).

26 Perry's conclusion that indexicals are essential is commonly accepted, including by Mellor (e.g. 1981b: ch. 5). 
' $12 \mathrm{pm}$ is now'. It appears that the professor needs a tensed belief to explain his action just as Prior needs one to explain his emotion.

To draw out the similarity in more detail, one could in fact imagine a professor forming a tenseless belief and hence leaving his office despite lacking any relevant tensed belief. Though, of course, the professor would be acting irrationally if he did so. It would be like a case in which the professor formed the belief 'two plus two is equal to four' and hence left for the meeting. ${ }^{27}$ (Even if an agent must be rational in the majority of his actions in order for us to be able to recognize the reasons that he acts for, we can and regularly do recognize people acting for bad or irrelevant reasons). ${ }^{28}$ What this highlights is that we are seeking a rationalizing explanation of the professor's action. One which understands it in terms of the reasons he acts for and, moreover, one that makes his action appear rational. Without the tensed belief we struggle to do this. ${ }^{29} \mathrm{We}$ cannot make sense of the professor as a rational being. (As noted above, one can give different forms of explanation besides rationalizing ones. One could not give a rationalizing explanation of a planet's orbit.) In the case of the emotion we are again concerned with a rationalizing understanding in which the emotion can be seen as appropriate. It is this which cannot be done in the tenseless case, just as it could not be done with the professor. ${ }^{30}$ We ought to note that Perry's essential indexical is specifically essential for rational actions of a timely nature and in a connected manner it is essential for appropriate emotions of a timely nature.

If no tenseless emotion of relief is appropriate, then no tenseless emotion of relief is justified by the fact it has as object. But, if any emotions of relief have tenseless facts as objects then tenseless emotions of relief do. This entails that no tenseless facts justify tenseless emotions of relief and it implies that no tenseless facts justify any emotions of relief. It is implausible that a tensed emotion of relief would have

\footnotetext{
27 A third sort of case would be one in which the professor underwent the bodily movements of leaving his office because he was being physically manipulated by security staff. In this case, unlike the irrational case, however, it appears that we are no longer looking at an action of the professor's, insofar as an action appears to be a specific type of bodily movement (cf. Anscombe 2000, who describes an action as behaviour we can explain with reference to the agent's reasons).

28 Cf. Wason (1966) for a much discussed case of recognised irrationality.

29 Without reference to the professor's beliefs we struggle to see his movements as responsive to reasons [to see them as actions] and without the professor's tensed beliefs his movements are not appropriately responsive to reasons, he is not rational. This is a very important point and when mated with an externalism about reasons for action affords room for a criticism of Perry's response to the essential indexical much like the criticism I am giving here of the Mellor/MacBeath response to Prior's argument. Cf. my Pearson (2015).

30 If one thinks of the related case of the first-personal indexical, one might remember that Perry says that the belief 'De Gaulle is making a mess', might play a role in explaining Perry's stopping, if Perry also believes 'I am De Gaulle'. So perhaps one could have a tenseless emotion which was appropriate, if one also had a tensed belief. For example, if one was relieved that 'the end of the exams is[tenseless] 12 pm', and one believed that 'it is now 1 pm'. However, this will not do. The explanation of Perry's act must include both the first- and third-personal beliefs. Without them it appears irrational. Similarly, the explanation of the emotion must include the tensed element, without it the emotion appears inappropriate. But, the object of the emotion is here specifically the reason the emotion is had for, that which could rationalize it, hence, the emotion must be tensed (if appropriate). It being 1 pm now is [part of] why one is relieved, that is, one is [in part] relieved that it is $1 \mathrm{pm}$ now.
} 
as its object a tenseless fact that no tenseless emotion of relief could. It follows that any tenseless fact a tensed emotion is responsive to is a fact a tenseless emotion could be responsive to. Given the object of an emotion is the sole ground of its appropriateness and a person's tensed and tenseless reliefs could be sensitive to the same tenseless facts - that is share objects-the reliefs' appropriateness must coincide. If no tenseless relief is justified, then neither is any tensed relief. It follows that if one supposes that the object of Prior's relief is a tenseless object, then one cannot use that object to account for the appropriateness of his relief, contrary to the externalist view reflected in our everyday approach to emotions.

In a connected manner, it is implausible that Prior would be motivated by a tenseless fact or in other words that a tenseless fact could be the object of his relief. This is because if the object of an instance of relief is a tenseless fact, then that relief is not justified by that object. But it is implausible that one is motivated in a majority of instances by things that do not justify those instances. Yet, the account being considered would have to make this generalisation given that most of our emotions are tensed and it is intended to be a general account. Here, as elsewhere, a principle of charity must underlie interpersonal understanding. ${ }^{31}$ We cannot recognize the beliefs of someone and also that most of these beliefs are irrational by our standards and similarly we cannot recognize the emotions of someone and that most of their emotions are inappropriate or unjustified by our standards. (Someone who says "I'm relieved" when and only when a distant stranger says "apple" is someone who appears not to be relieved at all.) Additionally, it appears that one needs little more than to be made aware of the object of their relief to be motivated to feel relieved and so it would be odd if Prior was aware of a tenseless fact which was the object of his relief long before he was relieved.

In giving this argument I have supposed that relief, as a general category of emotion, will have certain justificatory reasons. This assumption coincides with our general treatment of relief as a category of emotion that concerns a response to discomfort and is made appropriate in this responsiveness. Similar points apply to other emotions: fear concerns danger, anger concerns wrong doing, grief concerns loss, and so on. Furthermore, these distinctions are used by some to delineate forms of emotions, for example, it is in part because an emotion concerns a danger that we can identify that emotion as an instance of fear. ${ }^{32}$ Although tenseless and tensed emotions of relief require different expression they are nevertheless both instances of relief and as such are identical in their concern for discomfort. It is therefore not an adequate response to my argument to distinguish tenseless and tensed instances of relief as distinct forms of emotion, suggesting that one fact might be a justificatory reason for tensed emotions of relief and not for tenseless emotions of relief. In order to make this response to my argument work one would have to alter the current taxonomy of emotions. Whilst such an alteration is possible it would require independent justification without which this response to my argument is unfounded.

\footnotetext{
${ }^{31}$ Cf. Davidson (2001b: 137) (and perhaps Wittgenstein 2001: part I, Sects. 241 and 242).

32 Cf. Deonna and Teroni (2012: 41).
} 
Therefore, if we adopt a tenseless theory we cannot account for the appropriateness of Prior's relief in terms of the object of his relief-the reason for which he became relieved. If the object is tensed but does not exist, Prior's emotion is not appropriate as its object does not exist. Alternatively, if the object is tenseless, Prior's emotion is not appropriate because tenseless facts do not make instances of relief which have them as objects appropriate. But, it is natural to take the object of Prior's emotion to play the role of making his emotion appropriate. $\mathrm{He}$ is appropriately relived if and only if the object of his relief obtains. ${ }^{33}$ If one is relieved that the exams are over and the exams are over, then one's relief is justified and appropriate, as Prior's is. Conversely, if they are not over, one should not be relieved. The tenseless theory is thus inadequate as it has done nothing to address this natural and plausible idea with which it is incompatible.

\section{Inadequacies of the Mellor/MacBeath account}

The Mellor/MacBeath theory does offer an alternative account for why it is that Prior's relief is appropriate. As already noted, it refers to the brute fact that relief about an event that is after that event is justified. But, if this is said by the tenseless theorist we do not have an account that is on a par with the account that a tensed theorist can offer (contra Mellor 1981b: 50, a, 1998: 42). The tenseless and tensed accounts of the justification of Prior's relief both rely on brute facts (in the former case, that relief is justified after the exams, in the latter that it is justified when the exams are past). But, the tensed theorist offers us more besides this fact. S/he also offers us a story of the manner in which this fact has import to the situation. The fact that the exams are past makes the relief that they are past appropriate as this fact is the object of that reliefthe reason it was formed for. The Mellor/MacBeath theorist, however, offers no explanation of this form. As a result, they also offer no explanation of why our everyday talk fits the externalism about emotions outlined above or of why we say that "Prior is, quite righty, relived because the exams are over".

The Mellor/MacBeath tenseless theory cannot say, as surely we would, that "one ought to be relieved because the exams are over". According to the Mellor/MacBeath theory this utterance picks out nothing to justify relief. According to the utterance the ground for the appropriateness of the relief is given by the clause 'the exams are over'. According to the Mellor/MacBeath account this clause picks out the fact that the exams end before that utterance or before a particular time, $t$ (where $t$ happens to be the time the utterance was made). However, on the Mellor/MacBeath theory these facts are not what makes a feeling of relief justified. A feeling of relief is justified if that relief is after the end of a discomfort. At best we have some sort of pragmatic implication of a subjunctive conditional such as 'if you were relieved simultaneously with this statement then your relief would be justified' or 'if you were relieved at time $t$ then your relief would be justified'. But there appears to be nothing subjunctively

\footnotetext{
33 Actually, the matter is more complicated than this, as the object must also be something that justifies the emotion, but in the present case this condition is met.
} 
conditional about the idea that one ought to be relieved which is expressed by a statement like "one ought to be relieved because the exams are over". Nor does the instruction appear to be merely pragmatically given. Of course, one might understand an utterance like 'one ought to be relieved because the exams are over' less literally and hence in a way more charitable to the Mellor/MacBeath account. However, the point is that reasons must be given for giving this non-literal translation and until they are the Mellor/MacBeath account is on the back-foot.

An alternative tenseless account of the appropriateness of emotions has been offered according to which an emotion's appropriateness stems from its causal efficacy and the evolutionary advantage it offers. ${ }^{34}$ For example, an emotion of fear can cause one to avoid a danger that follows it thereby prolonging the life of the agent. However, an emotion of fear that concerns a danger that precedes that emotion will have no such evolutionary advantage and so is inappropriate. Being scared now won't help me avoid the car speeding towards me yesterday.

Such an account faces a similar objection to the one just outlined in response to the Mellor/MacBeath account. In particular, what would make an instance of relief appropriate according to this account would be certain facts concerning causation and evolutionary advantage bestowed on agents and these are not directly picked out by the clause 'the exams are over' in an utterance of "one ought to be relieved because the exams are over". The evolutionary account is, in this way, put at an initial disadvantage when compared to the everyday account of emotions presented in Sect. 3. This is not sufficient to show the evolutionary account to be false, nevertheless the point to note is that this is one of many instances in which the evolutionary account of emotions differs from the everyday account considered in this paper. In order for the evolutionary account to be offered as a response to the arguments of this paper one must therefore argue the case that the evolutionary account of emotions is correct whilst the everyday account is false.

This paper is not the place for an extensive critique of different theories of emotions, but I shall briefly raise a second reason for doubting the adequacy of the evolutionary account. Specifically, the evolutionary account is based on causation and a distinction between what follows or what precedes an emotion. However, the appropriateness of an emotion, as noted above, in part follows a different distinction, namely that between a tensed and a tenseless emotion. The tensed/tenseless distinction is distinct from and cuts across the follows/precedes distinction. One can have either a tensed or tensless emotion about something that follows it or about something that precedes it. The follows/precedes distinction therefore cannot account for differences in appropriateness that follow the former distinction. The evolutionary account therefore must be mistaken in locating the source of the appropriateness of emotions solely in the causal efficacy of those emotions. The current evolutionary account is at best incomplete. On the other hand, grounding the appropriateness of an emotion in its object as externalism does suffers no such difficulties because this object may itself be tensed (and have certain causal potentialities).

\footnotetext{
34 Cf. for example, Maclaurin and Dyke (2002), Dyke and Maclaurin (2013), and, Suhler and Callender (2012).
} 


\section{Conclusion}

The argument of this paper has the following form: our everyday practice suggests that emotions are motivated by facts and are appropriate if these facts justify those emotions; hence, if two emotions of relief differ in their appropriateness, then they must be motivated by different facts; Prior's thank goodness case shows that tensed and tenseless emotions of relief differ in their appropriateness; therefore, tensed and tenseless emotions of relief must concern different facts; the tensed theory of time is thus vindicated. (Given the closeness between the cognitive component of an emotion and a belief we might also say that tensed beliefs must concern different facts to tenseless beliefs.)

It is important to notice that this argument is unaffected by the non-extensionality of propositional attitudes. It does not base its conclusion on the fact that tensed and tenseless emotions have different meanings or contents. It merely requires one to be able to distinguish tensed and tenseless emotions, to recognize that they differ in whether or not they are appropriate, and that whether or not an emotion is appropriate is determined by its object.

This argument establishes a number of important points. First, it shows that there can be an argument from emotions to a tensed theory of time if emotions are made appropriate by their responsiveness to the world. Second, it shows that the common Mellor/MacBeath response to Prior's case is inadequate. This paper perhaps falls short of establishing the tensed theory of time as that would require a more thorough defence of this theory of emotions. However, that such a theory of emotions has hope is supported by its fit with everyday practice and its resemblance to some views of the emotions that have recently been defended. ${ }^{35}$ One should not simply approach Prior's argument and the emotions separately. On the contrary, a full solution to the issues raised by Prior can only come about with a detailed account of the emotions and until this is provided Prior's argument may yet be found to have implications for the metaphysics of time.

Open Access This article is distributed under the terms of the Creative Commons Attribution 4.0 International License (http://creativecommons.org/licenses/by/4.0/), which permits unrestricted use, distribution, and reproduction in any medium, provided you give appropriate credit to the original author(s) and the source, provide a link to the Creative Commons license, and indicate if changes were made.

\section{References}

Alvarez, M. (2008). Reasons and the ambiguity of 'belief'. Philosophical Explorations, 11, 53-65.

Alvarez, M. (2009). How many kinds of reasons? Philosophical Explorations, 12, 181-193.

Alvarez, M. (2010). Kinds of reasons: An essay in the philosophy of action. Oxford: Oxford University Press.

Anscombe, G. E. M. (2000). Intention. London: Harvard University Press.

Broad, C. D. (1938). An examination of McTaggart's philosophy (Vol. II). London: Cambridge University Press.

$\overline{35}$ Cf, for example, Deonna and Teroni (2012) and Greenspan (2004). 
Broome, J. (2001). Are intentions reasons? And how should we cope with incommensurable values? In C. Morris \& A. Ripstein (Eds.), Practical rationality and preference: Essays for David Gauthier (pp. 98-120). Cambridge: Cambridge University Press.

Cockburn, D. (1998). Tense and emotion. In R. Le Poidevin (Ed.), Questions of time and tense (pp. 77-91). Oxford: Oxford University Press.

Damasio, A. (2000). The feeling of what happens: Body, emotion and the making of consciousness. London: Vintage.

Dancy, J. (2000). Practical reality. Oxford: Oxford University Press.

Davidson, D. (2001a). Actions, reasons, and causes. Essays on actions and events (pp. 3-19). Oxford: Oxford University Press.

Davidson, D. (2001b). Radical interpretation. Inquiries into truth and interpretation (pp. 125-139). Oxford: Oxford University Press.

Deonna, J. A., \& Teroni, F. (2012). The emotions: A philosophical introduction. Abingdon: Routledge.

Dyke, H., \& Maclaurin, J. (2013). Evolutionary explanations of temporal experience. In H. Dyke \& A. Bardon (Eds.), A companion to the philosophy of time (pp. 521-534). Oxford: Wiley Blackwell.

Goodman, N. (1951). The structure of appearance. Cambridge, Massachusetts: Harvard University Press.

Greenspan, P. S. (2004). Practical reasoning and emotion. In A. Mele \& P. Rawling (Eds.), The oxford handbook of rationality (pp. 206-221). Oxford: Oxford University Press.

Hoerl, C. (2013). Tense and the psychology of relief. Topoi (special issue on time and time experience, Torrengo, G., \& Ciuni, R. (eds.): 1-15.

Kaplan, D. (1989). Demonstratives. In J. Almog, J. Perry, \& H. Wettstein (Eds.), Themes from Kaplan (pp. 481-563). Oxford: Oxford University Press.

Kolodny, N. (2005). Why be rational? Mind, 114, 509-563.

Kolodny, N. (2008). The myth of practical consistency. European Journal of Philosophy, 16, 366-402.

Lowe, E. J. (2009). An essentialist approach to truth-making. In E. J. Lowe \& A. Rami (Eds.), Truth and truth-making. Stocksfield: Acumen.

MacBeath, M. (1983). Mellor's Emeritus headache. Ratio, 25, 81-88.

Maclaurin, J., \& Dyke, H. (2002). Thank goodness that's over: The evolutionary story. Ratio, 15, 276-292.

Mellor, D. H. (1981a). Thank goodness that's over. Ratio, 23, 20-30.

Mellor, D. H. (1981b). Real time. Cambridge: Cambridge University Press.

Mellor, D. H. (1983). MacBeath's soluble aspirin. Ratio, 25, 89-92.

Mellor, D. H. (1998). Real time II. London: Routledge.

Oaklander, N., \& Smith, Q. (1994). The new theory of time. London: Yale University Press.

Pearson, O. (2015). Rationality and the first person. The Journal of Consciousness Studies, 22(11-12), $132-148$.

Perry, J. (1979). The problem of the essential indexical. Nous, 13, 3-21.

Prior, A. N. (1959). Thank goodness that's over. Philosophy, 34, 12-17.

Prior, A. N. (1962). The formalities of omniscience. Philosophy, 37, 114-129.

Reichenbach, H. (1948). Elements of symbolic logic. New York: Macmillan.

Russell, B. (1906). Review of 'symbolic logic and its applications' By Hugh MacColl. Mind, 15, $255-260$.

Solomon, R. (1993). The passions (2nd ed.). Indianapolis: Hackett.

Solomon, R. (2004). Emotions, thoughts, and feelings: Emotions as engagements with the world. In R. Solomon (Ed.), Thinking about feeling (pp. 76-88). Oxford: Oxford University Press.

Suhler, C., \& Callender, C. (2012). Thank goodness that argument is over: Explaining the temporal value asymmetry. Philosophers Imprint, 12(15), 1-16.

Wason, P. C. (1966). Reasoning. In B. M. Foss (Ed.), New horizons in psychology (Vol. I, pp. 135-151). Harmandsworth: Penguin.

Williams, B. (1979). Internal and external reasons. In R. Harrison (Ed.), Rational action: Studies in philosophy and social science (pp. 17-28). Cambridge: Cambridge University Press.

Wittgenstein, L. (2001). Philosophical investigations. Translated by G. E. M. Anscombe. Oxford: Blackwell. 